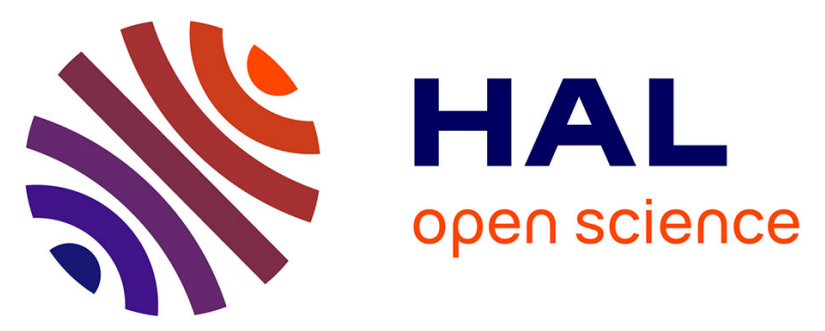

\title{
Simulation, dans le cadre de l'Agenda 2000, d'un rééquilibrage des aides directes privilégiant les soutiens à la gestion de l'espace \\ G. Bazin, F. Colson, Vincent Chatellier
}

\section{- To cite this version:}

G. Bazin, F. Colson, Vincent Chatellier. Simulation, dans le cadre de l'Agenda 2000, d'un rééquilibrage des aides directes privilégiant les soutiens à la gestion de l'espace. Colloque: Les mesures agrienvironnementales. Premiers bilans des expériences européennes, Société Française d'Economie Rurale (SFER). FRA., Nov 1997, Paris, France. 11 p. hal-02836683

\section{HAL Id: hal-02836683 \\ https://hal.inrae.fr/hal-02836683}

Submitted on 7 Jun 2020

HAL is a multi-disciplinary open access archive for the deposit and dissemination of scientific research documents, whether they are published or not. The documents may come from teaching and research institutions in France or abroad, or from public or private research centers.
L'archive ouverte pluridisciplinaire HAL, est destinée au dépôt et à la diffusion de documents scientifiques de niveau recherche, publiés ou non, émanant des établissements d'enseignement et de recherche français ou étrangers, des laboratoires publics ou privés. 


\section{Simulations, dans le cadre de l'Agenda 2000, d'un rééquilibrage des aides directes à l'agriculture française privilégiant les soutiens à la gestion de l'espace \\ - . . . . . \\ Gilles BAZIN (INRA ESR Grignon) - François COLSON et Vincent CHATELLIER (INRA ESR - Nantes)}

L'objet de cette communication est d'analyser les effets de la prochaine réforme de la Politique agricole commune (Agenda 2000) sur la répartition des aides directes aux exploitations agricoles françaises. Elle vise, dans ce cadre, à simuler une redistribution des aides en faveur de la gestion de l'espace (prime à l'herbe et indemnités compensatoires de handicaps géographiques) suite à l'application d'un plafonnement des aides PAC par exploitation.

La réforme de la Politique agricole commune (PAC), adoptée en mai 1992, a conduit à une forte augmentation des aides directes, notamment celles liées à la compensation des baisses de prix des céréales et de la viande bovine. En 1995, les aides spécifiques à la gestion de l'espace (MAE + ICHN) représentent $7 \%$ de l'ensemble des aides directes, soit 3,1 milliards de francs pour l'ensemble des exploitations représentées par le RICA. La prime à l'herbe concerne 73900 exploitations agricoles «professionnelles » dont 44300 en zone de montagne et 19600 dans les autres zones défavorisées. Les exploitations situées dans les zones de montagne ont un résultat courant moyen nettement inférieur à celui obtenu dans les exploitations de plaine (121 400 francs contre 213600 francs). Dans les zones de montagne, les aides spécifiques à la gestion de l'espace, qui représentent $40 \%$ des aides attribuées $(\mathrm{ICHN}=25000$ francs ; prime à l'herbe $=$ 10700 francs sur un total de 88400 francs soit $73 \%$ du résultat courant), ne compensent que partiellement les écarts observés dans la distribution des aides directes (106 500 francs en plaine soit $50 \%$ du résultat courant).

La simulation des propositions Agenda 2000 sur les données nationales du Réseau d'Information Comptable Agricole (RICA) montre, à structures et productivité constantes, une nouvelle augmentation du montant des aides directes dans la formation du revenu des exploitations agricoles $(+28400 \mathrm{~F}$ en moyenne nationale). France entière, le montant des aides par hectare (SCOP + SFP) passe de 2060 francs en 1996 à 2590 francs au terme de l'application du projet. Par hectare de grandes cultures le montant des aides COP (2 800 francs) demeure cependant supérieur à celui des aides animales (MAE et ICHN inclus) par hectare de surface fourragère (2060 francs).

La hiérarchie des revenus entre les zones est faiblement resserrée, le résultat final par exploitation s'élevant à 202300 francs en plaine et à 117500 francs en montagne. Pour ces dernières, la taille plus modeste et la spécialisation plus forte dans les activités bovines font que 
la dépendance à l'égard des aides directes est plus importante (la totalité du résultat courant moyen contre la moitié en plaine).

L'étude d'un plafonnement des aides de la PAC 2000 est envisagée dans le cadre de la proposition de principe émise par la Commission. Elle s'inscrit dans la perspective d'une plus grande équité dans la distribution des soutiens publics et d'une répartition plus équilibrée des emplois agricoles sur le territoire. Pour cela, un plafond de 50000 Écus par exploitation (plus un complément de 20000 Écus par actif agricole au delà de deux unités de main d'oeuvre par exploitation) est simulé. Le montant des crédits rendus disponibles par ce plafonnement (3,8 milliards de francs en France) est ensuite utilisé pour revaloriser les aides spécifiques à la gestion de l'espace (MAE et ICHN), dont le montant actuel est multiplié par 2,2.

Ce seuil de plafonnement des aides PAC concerne 27900 exploitations agricoles, soit $7 \%$ des exploitations professionnelles françaises. Elles sont spécialisées pour $70 \%$ d'entre elles dans l'orientation céréales et grandes cultures et localisées pour $60 \%$ d'entre elles dans seulement cinq régions : Centre, Bourgogne, Champagne-Ardenne, Picardie, Lorraine. Le plafonnement simulé conduit à la redistribution d'un tiers de leur revenu, qui passe à 222000 francs par exploitation. Le report des crédits disponibles sur les aides à la gestion du territoire induit une hausse significative du revenu des exploitations de montagne (+ 43700 francs) et une diminution de moitié de la différence des revenus moyens plaine-montagne, qui s'élève respectivement à 192400 et 159800 francs. Cet exemple de simulation montre qu'une redistribution des soutiens en faveur de la gestion de l'espace peut conduire à une réduction importante des disparités de revenu agricole entre exploitations et entre régions. 